\title{
El múltiple Aristóteles \\ Una visión de la filosofía práctica aristotélica desde la problemática contemporánea
}

\author{
OSVALDO GUARIGLIA \\ Centro de Investigaciones Filosóficas, CONICET \\ y Universidad de Buenos Aires
}

El presente trabajo intenta transmitir las sutiles uniones de la problemática filosófica contemporánea con la filosofía práctica aristotélica, cuyos temas continúan siendo fundamentalmente los temas actuales de discusión. En la teoría de la acción, dentro del horizonte wittgensteiniano, las aporias suscitadas por la concepción "pictórica» de la proposición en su relación con el mundo, al abordar hechos tales como el deseo, la voluntad y la acción, reciben importante ayuda de la filosofía práctica aristotélica para explicar las macro-acciones, como las que protagonizamos en nuestra vida cotidiana de relación, frente a otras corrientes que pretenden, mediante reducciones, sustracciones y otros modos de secciona- miento artificial, aislar una especie de micro-elemento, la acción básica, directamente impenetrable a toda forma de comprensión. Por otra parte, la reactualización -acaso menos feliz- de la ética institucional de Aristóteles pone el acento en una cuestión irresuelta de toda moral universalista: su corporización en las estructuras del «mundo de la vidan. El modelo aristotélico tiene la ventaja sobre los otros -neohegelianos, comunitarios, etc.-, de trazar transparentemente el entrecruzamiento entre sistemas de acción colectiva, normas consuetudinarias y formas de organización social y política (las famosas constituciones), sin partir de ninguna posición filosófico-histórica previamente tomada.

Trazar un cuadro de las distintas líneas filosóficas que en la actualidad hacen remontar su genealogía espiritual al mismo Estagirita es, sin duda, una tarea no sólo fatigosa sino, por añadidura, vana. En efecto, además de las corrientes que, como el tomismo, pretenden ser una continuación ininterrumpida de la renovación aristotélica desde el siglo xII hasta la fecha, existen otras cuya filiación, no siendo tan directa, no deja, sin embargo, lugar a dudas. Ésta se da a conocer por medio de un conjunto de influencias indirectas, dispersas, que comprenden sea una familia de disciplinas (como la filosofía práctica) sea un cierto estilo de hacer filosofía (como el análisis del lenguaje ordinario), todas las cuales pueden ser retrotraídas en última instancia a algún aspecto del pensamiento aristo- 
télico. Por último, está la actividad filológica, que, desde la reedición del monumental Corpus Aristotelicum al comienzo del siglo pasado por obra de I. Bekker en adelante, no ha cesado de producir nuevos trabajos ya sea de carácter estrictamente filológico, ya de carácter hermenéutico, que en su conjunto han fijado y extendido nuestro conocimiento tanto de la obra aristotélica como de su influencia más directa en los siglos IV y III a.C. ${ }^{1}$

No es, por cierto, mi intención pasar revista a todas estas corrientes ni, menos aún, dar una especie de informe bibliográfico comentado como los que proporcionan algunas revistas especializadas sobre la Antigüedad clásica - en especial Lustrum. Me propongo, en cambio, realizar un ejercicio más personal y, espero, más instructivo desde el ángulo filosófico: recrear aquellos problemas dentro del ámbito de la filosofía práctica actual en los cuales la influencia del pensamiento aristotélico se hace aún sentir de modo perceptible. Para ello, es necesario recrear al mismo tiempo el clima intelectual contemporáneo dentro del cual, en cada caso, se conformó un suelo propicio para que la semilla proveniente de la planta del Perípato volviera a germinar.

2.1. La filosofía de la acción. El origen del renacimiento del interés contemporáneo por la filosofía de la acción debe buscarse, en primer lugar, en los enigmas que envuelven las observaciones hechas por Wittgenstein hacia el final del Tractatus sobre la voluntad, el mundo y la acción. En efecto, la afirmación que lleva el número 6.4 sostiene: «Todas las proposiciones tienen el mismo valor", lo que es un resultado necesario de la concepción "pictórica" de las proposiciones, de acuerdo con la cual ninguna parte dèl mundo puede ser antepuesta a otra. ¿Qué ocurre, entonces, con la voluntad? En dos sentencias, 6.373 y 6.374 , Wittgenstein expresa de un modo tajante su posición al respecto: "El mundo es independiente de mi voluntad» y «aun cuando todo lo que deseáramos sucediera, esto sería, por cierto, sólo una gracia del destino, por así decirlo, pues no hay ninguna conexión lógica entre la voluntad y el mundo que garantice eso [...]", ${ }^{2}$ La contracara de esta convicción es confiada a su libro de notas: en una larga disquisición sobre el tema, que anticipa algunas de sus concepciones posteriores, Wittgenstein sostiene todavía lo siguiente: «Pues al contemplar la voluntad, parece como si una parte del mundo estuviera más próxima a mí que otra (lo que sería insoportable)». ${ }^{3}$ ¿Qué tiene ello de insoportable? De acuerdo con Winch, la explicación debe buscarse en el papel asignado a la proposición en el Tractatus. Pues, dado que ésta es una imagen del estado de cosas en el mundo, su relación entre éste y la proposición es siempre la misma, tal como se 
puede comprobar mediante una comparación entre ella y la realidad. La relación que se establece entre la proposición y el mundo a través de la voluntad no encaja, empero, con este esquema: yo puedo formular la proposición, pero luego no puedo descubrir si ella es verdadera o falsa a través de una comparación con el mundo. ${ }^{4}$ Así se engendra el enigma al que Wittgenstein tratará de dar respuesta en las Investigaciones filosóficas y a partir del cual se desarrolla una línea de pensamiento que nos conduce, a través de G.E.M. Anscombe y A. Kenny, hasta Aristóteles.

Un parágrafo de las Investigaciones resume la posición que adopta finalmente Wittgenstein con respecto a la acción, la que, a su vez, constituirá el centro de la reflexión de sus discípulos ( $\$ 615)$ : «La voluntad, si no fuera una especie de deseo, debe ser la acción misma. No puede quedar detenida antes de la acción. Si es la acción, lo es en el sentido habitual del término, es decir: hablar, escribir, caminar, levantar algo, representarse algo. Pero también, intentar, procurar, preocuparse por hablar, escribir, levantar algo, representarse algo, ctc. $n^{5} \mathrm{El}$ misterio que ahora se devela es el de la existencia separada de la voluntad como una entidad «mental» situada en ninguna parte, que precede $o$ "causa» la acción. La voluntad se funde en adelante con la acción misma y a través de ésta se relaciona con el mundo. ${ }^{6} \mathrm{El}$ problema que se presenta, entonces, es el de dilucidar esta relación. Anscombe nos revela las dificultades que tuvo que superar antes de llegar a su propuesta definitiva en los siguientes términos: "Yo misma, al considerar estos problemas, busqué anteriormente la salida en la siguiente fórmula: yo hago lo que ocurre. Es decir, cuando la descripción de lo que ocurre es la misma cosa que yo diría que yo es. taba haciendo, entonces no hay distinción entre mi acción y las cosas que ocurren. Pero todo el que oía esta fórmula la encontraba extremadamente paradójica y oscura. Y pienso que la razón es la siguiente: lo que ocurre debe ser captado por la observación, pero he argüido que mi conocimiento de lo que hago no se da por medio de la observación".

Así planteado el problema, la solución aristotélica recobra, de pronto, toda la penetración que un largo desgaste a través de veintitrés siglos de interpretación erudita le había quitado. En efecto, la propuesta de invertir la dirección del ajuste de la proposición, de modo tal que sea el mundo el que es puesto a prueba, calza de un modo tan apropiado dentro de los términos del dilema wittgensteniano como si fuera una respuesta preparada para él. El ejemplo clásico es el de quien se equivoca al escribir su nombre: en este caso, el error no se da en la proposición, sino en la acción que la lleva a cabo. ${ }^{8}$ Pero con ello emergía, nuevamente, la olvidada temática del conocimiento práctico que desde Descartes había sido desterrada de la filosofía moderna por un prejuicio contemplativo, cuyas raíces se hunden en las malformaciones de la razón subjetiva surgida con la modernidad. 
2.2. El paralelo entre la situación en que se encontraba la filosofía analítica contemporánea hacia mitad de este siglo y el punto de partida de la filosofía aristotélica de la acción no proviene de una simple analogía entre posiciones filosóficas de por sí bastante distanciadas, como las que se suelen hacer con fines generalmente didácticos. Surge, más bien, de un estricto paralelo entre dos situaciones filosóficas estrechamente conectadas: la de la filosofía platónica, especialmente la de su último periodo, incluyendo la teoría no escrita, y la filosofía del atomismo lógico y su teoría semántica de cuño platónico. Especialmente notable se hace esta similitud en el intento de liberarse de una coraza que impedía todo movimiento libre en las observaciones de Aristóteles y de Wittgenstein sobre la exactitud en la $E N$ y en las Investigaciones filosóficas respectivamente. En efecto, frente a cualquier exigencia que vaya más allá de lo posible, el Estagirita advierte que «es, en efecto, un signo de cultura el exigir de cada género sólo aquella exactitud que la naturaleza del asunto permite. Pues parece tan absurdo el pedir a un matemático un discurso persuasivo como el exigir de un orador una demostración necesaria»(1.094b 12-27). De la misma manera, frente al postulado sostenido en el Tractatus, de acuerdo con el cual una proposición debe tener un sentido absolutamente determinado con prescindencia de su inserción en el discurso humano, se pregunta ahora Wittgenstein: « $i$ Es inexacto cuando doy la distancia que nos separa del sol con la aproximación de $1 \mathrm{~m}$ ?, ¿o cuando doy al ebanista el ancho de la mesa con una aproximación de $0,001 \mathrm{~mm}$ ? No hay fijado $u n$ ideal de exactitud: - se responde- no sabemos qué deberíamos entender por tal cosa ${ }^{9}$ De la misma manera que en el ejemplo aristotélico, se pone aquí el acento en el encadenamiento que sujeta fuertemente todo sentido de una proposición con su función en el lenguaje ordinario: una será la que cumple en el lenguaje matemático, como el paso necesario en un razonamiento deductivo; otra, la que desempeña en el lenguaje retórico, cuya finalidad (la persuasión) exige cánones propios.

Como he señalado en un trabajo anterior, ${ }^{10}$ Aristóteles sostiene coherentemente la igualdad en la estructura ontológica de las proposiciones de creencia (éndoxa) que intercambiamos en nuestras interacciones diarias y las acciones (práxeis). Ambas, en efecto, son dependientes del contexto y poseen una estructura teleológica: en las acciones, en relación con el agente que las realiza, mientras que en las opiniones, por la remisión implícita al sujeto que inevitablemente realizan. Es posible que, a medida que avancemos en el análisis del concepto aristotélico de acción, el correlato que yo veo entre los puntos de partida de la moderna y de la antigua filosofía de la acción se vayan haciendo más evidentes.

Ahora bien, para reconstruir la filosofía aristotélica de la acción, se hace necesario comenzar por la noción misma y por los esfuerzos deno- 
dados que el filósofo debió realizar para independizarla de los filosofemas en que estaba encastrada. La complejidad del concepto, sin embargo, sólo va apareciendo de modo paulatino a través del tejido lógico y semántico que lo une con otras cadenas de conceptos, de los cuales aparece al comienzo totalmente independizado. Voy a sintetizar estos aspectos significativos del término, que están conceptualmente unidos, en las tres características siguientes: 1) independencia de otro tipo de entidades; 2) dependencia estricta de un ser humano como "principio y causa» de ella (aspecto "voluntario" de la acción); 3) interrelación entre el aspecto deliberativo (boúleusis) y el aspecto desiderativo (prohairesis), que permite sólo mediante su conjunción identificar una acción como una acción tal...

1) En el capítulo de $E E$ II 6 (1.222b 15-1.223a 9), Aristóteles discute extensamente las condiciones necesarias de la acción que resulta moralmente relevante. Lo que allí expone, constituye el cuadro más completo de los supuestos generales de la acción, comenzando por la delimitación conceptual de ésta. Para ello, Aristóteles tiene que confrontarse con la teoría platónica, cuyos rasgos más característicos y permanentes pueden ser tomados de la exposición del Filebo 23c-27a. De acuerdo con ésta, existen dos especies de fenómenos en el mundo: aquéllos que poseen un carácter definido, una medida precisa y una completa invariabilidad, como las magnitudes numéricas, geométricas, etc., y otros que están en constante cambio, que tan pronto llegan a ser como desaparecen de la existencia o varían continuamente en intensidad y gradualidad, de modo que resulta imposible evitar una constante indeterminación, por ejemplo, de los precisos límites entre el calor y el frío, o entre humedad y sequía, etc. A esta última clase pertenecen las sensaciones psicofísicas del hombre y, en general, las pasiones, etc. Ahora bien, sólo puede tener existencia permanente, racional y verdadera aquello que es invariable, de lo cual puede haber conocimiento exacto y preciso; de la otra clase, podrá haber conocimiento en la medida en que participe, mediante mezcla con la clase de lo invariable, de las características de éste y se pueda establecer una proporción numérica que pueda ser fijada en una cantidad y, como tal, conocida. ¿Qué papel le corresponde dentro de esta bipartición a la prâxis? Platón no lo dice directamente, pero se puede extraer su respuesta muy fácilmente tanto del excursus sobre el método al comienzo del diálogo (Phil. 16c y ss.) como de las características que le atribuye a todo lo relacionado con lo humano. La prâxis es subsumida bajo el concepto más general de téchne como una especie de ésta. No es difícil comprender por qué razón la téchne constituye para Platón el modelo por antonomasia tanto de la producción como de la acción o de la misma generación natural. En efecto, en ella aparecen estrechamente combinados dos elementos heterogéneos: la pura teoría que expone relaciones 
universalmente válidas y la aplicación de esa teoría sobre un segundo elemento, impreciso y rebelde a la medida, que sólo puede presentar una reproducción imperfecta, imprecisa y aproximada del modelo teórico. Como señaló con razón Gaiser, esta estructura es la misma, ya sea que se trate de la téchne divina que ha construido el cosmos, ya sea de la téchne humana, que imita por medio de las ideas técnico-matemáticas en el alma la estructura ontológica última del mundo." Ahora bien, dado que nuestro cuerpo exhibe la misma composición atómica que el universo (Phil. 28d-31a), la sabiduría de la vida no diferirá del conocimiento científico de la estructura exacta del universo. Tanto para el uno como para el otro, el conocimiento y la norma apropiada a él surgirán de la deducción de las relaciones matemáticas a partir de los principios, relaciones que en cada caso establecerán el grado de verdad, de realidad y de bondad a que se puede llegar.

A fin de desmantelar esta argumentación, Aristóteles comienza estableciendo ciertas diferencias entre los significados del término "principio» (arché), sobre las cuales se apoyará su rechazo ulterior de toda entidad matemática como comienzo de una acción. En efecto, en sentido estricto, "principio" se dice exclusivamente "de aquello de lo cual se origina un movimiento (físico)» ( $E E$ 1.222b 21-24); en otros términos, solamente hay principio en sentido propio cuando tiene lugar a continuación sea una traslación en el espacio, sea un cambio cualitativo, sea la generación de una nueva sustancia. De este modo, Aristóteles establece un criterio de analiticidad para el significado del término arché que le permitirá distinguir entre un sentido propio, que se aplica exclusivamente a: (a) los movimientos naturales; (b) los movimientos no naturales - las acciones en general- $\mathrm{y}(\mathrm{c})$ un sentido meramente analógico o impropio (homónimo), que es el que tienen los «principios» de las entidades invariables como las matemáticas. De este modo, Aristóteles está en condiciones de formular una de las condiciones determinantes del concepto de acción:

De ello se sigue que, si existen ciertos entes que pueden ser de un modo o de modo (directamente) contrario, es necesario que los principios de éstos tengan también las mismas características: en efecto, lo que proviene de proposiciones necesarias es también necesario, lo que en cambio se origina de aquellos otros principios tiene la posibilidad de transformarse en su contrario. Y lo que está en las manos de los propios hombres, pertenece en su gran mayoría a estos últimos entes, pasibles de ser de un modo u otro. De (todos) ellos los hombres son el principio. En consecuencia: todas aquellas acciones de las que el hombre es el principio y dueño absoluto pueden evidentemente tener o no tener lugar. Del mismo modo, es evidente que en su poder está el que tales acciones tengan o no lugar, dado que él es el dueño de que existan o no. De cuantas acciones está en su poder hacerlas o no hacerlas, él es la 
causa de las mismas, y de cuantas él es la causa, éstas están en su poder (EE $1.222 \mathrm{~b} 40-1.223 \mathrm{a} 9)^{12}$

La conclusión general que se extrae de este párrafo no sólo representa la posición permanente de Aristóteles, sino que constituye un basamento sobre el que debemos apoyarnos aún hoy para levantar una teoría filosófica de la acción. Pues lo que él sostiene es lo siguiente: la enorme mayoria de las cosas que está en poder de los hombres el hacer o no son (a) contingentes, es decir, pueden tener tanto un atributo como su contrario, tener lugar o no tener lugar; existe, sin embargo, una clase de cosas $(b)$ que dependen del hombre y que, si tienen lugar, tienen siempre una consecuencia necesaria: la reproducción (un hombre engendra a otro hombre). De ambas cosas el hombre es principio en sentido estricto, pero difiere en el modo en que es principio. En efecto, el hombre como principio de la formación de un nuevo organismo es una causa no absoluta, que, a su vez, ha sido causada, constituyendo sólo un eslabón en la cadena biológica de causas; como principio de lo que está en sus manos que tenga o no tenga lugar, el hombre es causa absoluta, no reductible a otra. Por lo tanto, él es la causa absoluta de las acciones y, a la inversa, que él sea la causa absoluta implica que está en su poder el realizarlas o no.

2) Como resultado de esta argumentación en favor de la independencia ontológica de las acciones y de su principio, el ser humano, Aristóteles obtiene una característica conceptual distintiva de las acciones qua acciones: el ser voluntarias: "es evidente que la excelencia y la bajeza tienen relación con aquellas acciones de las cuales nosotros somos no sólo la causa sino también el principio [...]. Todos coinciden en que somos causa (responsable) de aquellos actos que realizamos voluntariamente y por elección de cada uno, y de cuantas cosas realizamos involuntariamente no somos causa (responsable)" (EE 1.223a 15-18). La distinción entre acciones voluntarias e involuntarias involucra un largo capítulo, que no vamos a seguir aquí en detalle. Para simplificar, si entendemos por "voluntarias" aquellas acciones que realizamos tanto "de buen grado" como «a disgusto" y por involuntarias todas aquéllas que son "por fuerza" o "por ignorancia", entonces la clase de las acciones voluntarias tendrá la misma extensión que la de las acciones «intencionales» y formará parte del concepto mismo de «acción" ${ }^{13}$

\section{3)}

«Deliberamos sobre aquellas cosas que están en nuestro poder y que pueden ser realizadas por nosotros [...]. Ahora bien, cada uno de los hombres delibera sobre aquellas cosas que puede realizar él mismo. Y en el caso de las ciencias exactas [...] no hay deliberación [...], sino que deliberamos sobre lo que se origina por nosotros mismos pero no siempre de la misma manera, como por ejemplo 
sobre un tratamiento médico o el modo de obtener dinero. [...]. La deliberación [por lo tanto] tiene que ver con aquellas entidades que ocurren frecuentemente de una misma manera y que, sin embargo, no son completamente previsibles con relación a su repetición futura, o son directamente indeterminadas" (EN III 5 , $1.112 \mathrm{a} 30-1.112 \mathrm{~b} 9$ ).

Las relaciones entre «deliberación", «elección» y «sabiduría práctica" (phrónesis) han sido largamente debatidas durante el pasado cuarto de siglo, de modo que una discusión en detalle de las distintas interpretaciones exigiria de por sí un trabajo específico. ${ }^{14}$ Aquí me voy a limitar a aquellos rasgos más geperales que definen y conectan cada una de las tres facultades, así como al aporte final que éstas realizan al problema de la relación entre contenido proposicional y mundo.

Un somero análisis de la cita que antecede muestra que Aristóteles está estipulando lo que hoy describiríamos como las condiciones pragmáticas de emisión del verbo "deliberar". En efecto, cualquier proposición introducida por el verbo "deliberar» deberá sátisfacer determinados requisitos, que coinciden con los establecidos por Aristóteles: a) si t(i) es el tiempo de la emisión, la proposición objeto de deliberación deberá ocurrir en un $\mathrm{t}(\mathrm{j})$, tal que $\mathrm{i}<\mathrm{j}$ (en donde $«<»$ equivale a "anterior"); $b$ ) si $\mathrm{H}$ es el hablante que utiliza el verbo deliberar, entonces dentro de las condiciones de sentido impuestas para el contenido proposicional de $p$ (el objeto de la deliberación) está la siguiente: es físicamente posible que $\mathrm{H}$ realice $p ; \mathrm{y}$, por último, $c$ ) dentro de las condiciones de sinceridad del uso del verbo deliberar se sobreentiende que $\mathrm{H}$ está seriamente inclinado o resuelto a hacer $p$. Con este último paso hemos ingresado, siguiendo exclusivamente las relaciones conceptuales pragmáticas de «deliberar», en el siguiente punto, a saber: la conexión entre «deliberación» y «elección» (prohairesis). En efecto, forma parte del significado ilocucionario del verbo "deliberar" el hecho de que el hablante exprese una disposición inmediata a llevar a cabo el contenido proposicional $p$, que es objeto de deliberación. Desde este punto de vista, aquello sobre lo que delibero y aquello que me propongo o que me resuelvo a hacer son lo mismo: «Lo deliberado y lo elegido son la misma cosa; sólo que aquello que he elegido es algo ya determinado, puesto que es algo sobre lo que la deliberación ya ha concluido. En efecto, cada uno de nosotros deja de indagar cómo actuará cuando logra llevar el comienzo de la acción nuevamente hasta sí mismo" (EN III 5, 1.113a 2-6). A mi modo de ver, es dentro de este contexto que debemos entender el sentido último de expresiones compuestas como "deseo deliberativo" aplicadas a la elección, o, a la inversa, la deliberación como "juicio acompañado de deseo". Pues lo que Aristóteles quiere expresar, a mi juicio, es lo siguiente: la delibe- 
ración y la resolución son dos aspectos de una misma capacidad: el primero tiene que ver con el contenido doxástico de la proposición $p$ como una especie de acciones, reconocible de modo general como tal acción por la razón; el segundo tiene que ver con el aspecto efectivo de la acción que transforma el mundo de modo tal que en tiempo $t(j)$ posterior a la deliberación dé comienzo, a través de la causalidad de mi acción, el estado de cosas por el que me he resuelto, resolución que no es otra cosa que la misma acción. ${ }^{15}$

2.3. Desde fines del siglo pasado, arreció una disputa sobre la función última de la deliberación entre los especialistas: ¿incluye ésta el fin de la acción o se limita exclusivamente a considerar los medios para alcanzar aquél ? $^{16}$ La discusión no resultó, en este caso, meramente erudita, como la frondosa bibliografía acumulada en torno a la cronología relativa de la $E N$ y la $E E$ sobre la autenticidad de la $M M$, sino que tuvo como consécuencia la aclaración de un aspecto que resulta sumamente importante para entender el concepto mismo de «razonamiento práctico» aún hoy. En efecto, como he señalado en trabajos anteriores, lo que la deliberación presenta como su resultado es el reconocimiento de una acción determinada o de un estado del mundo (incluido nuestro propio cuerpo) a lograr mediante nuestra inmediata intervención como un bien. ${ }^{17} \mathrm{Y}$, como señala Wiggins, «el bien es la clase de cosas que nosotros deseamos porque lo pensamos como un bien, no algo que creemos bueno porque es lo que deseamos ${ }^{18}$ Pero pensar como buena una acción supone, por una parte, que disponemos de algo así como de una afirmación universal que conecta un tipo-genérico de acciones con el predicado «bueno» en determinadas circunstancias, la que constituirá la premisa mayor de un silogismo práctico. Por otra, el resultado de la deliberación, que culmina en la resolución, al reconducir la cuestión hasta nosotros mismos, nos vuelve a colocar en la situación de donde habíamos partido, pero con una importante diferencia: ahora el mundo frente a nosotros ha cambiado, en cierto modo, pues una parte de él ha cobrado una particular importancia, ya que corresponde a nuestra elección: «lo que en el pensamiento son afirmación y negación, esto son en el deseo persecución y rechazo; de modo que, puesto que la virtud moral es una disposición (héxis) electiva, y la elección un deseo deliberativo, es necesario por ello que el razonamiento sea verdadero y el deseo correcto, si la elección ha de ser buena, y que el primero afirme (que la acción a realizar es del tipo apropiado) y el segundo se la propongas (EN VI 2,1.139a 21-26).

La solución propuesta por Aristóteles al problema de la razón práctica asombra por su profundidad y sencillez. «Bueno» y «malo», afirma en De anima, están en el mismo género que "verdadero» $\mathrm{y}$ «falso", con la diferencia de que éstos difieren de modo absoluto y aquéllos siempre 
desde la perspectiva de un agente (III 7, 431b 10-11). En ambos casos, sin embargo, se trata de aquellos valores trascendentales respecto de los cuales se define una forma de razón. $\mathrm{Y}$ así como para tener acceso a la razón teórica necesitamos un sistema de signos que podamos conectar deductivamente mediante precisas reglas de inferencia, del mismo modo para tener acceso a la razón práctica se requiere no solamente la capacidad de actuar, sino también la de actuar bien, eupraxía. Porque deliberamos sobre lo que consideramos un bien, pero nuestras acciones, en tanto buenas, no solamente tienen sentido en sí mismas, como la realización de una determinada acción virtuosa, sino también como parte de un todo que es la propia vida. En otros términos, la deliberación está estrechamente ligada, en última instancia, a un ideal de vida que en cada caso se ha elegido como aquella vida que uno desea llevar como forma específica de florecimiento (profesional, artístico, deportivo, etc.)..$^{19}$

De esta manera, el desarrollo del problema del conocimiento práctico nos ha conducido, a través del concepto de acción, al concepto de «virtud "en su acepción más específica: como posesión de una capacidad para desarrollar una especie de acción en las circunstancias apropiadas. ${ }^{20}$ Hemos llegado, así, a la concepción «formal» de la virtud a través de su conexión analítica con el concepto de acción, de bien, de deliberación y de elección, que culminan en la sabiduría práctica (phrónesis). Es necesario destacar que esta concepción "formal" puede ser correcta independientemente de los tipos específicos de acciones que en cada circunstancia se consideran virtuosas. En efecto, en cada caso, el carácter de "virtuosa» o "viciosa» de una acción depende de los criterios sociales y culturales, históricamente vigentes; a su vez, el hecho de que una determinada acción sea considerada en una determinada circunstancia social, cultural e histórica como "virtuosa» (o «viciosa»), puede constituir un fundamento suficiente (o no) para sostener que, efectivamente, tal acción está moralmente justificada. En la filosofía ética contemporánea han cobrado fuerza en el último cuarto de siglo versiones rejuvenecidas de este «realismo» o «neoaristotelismo» moral, especialmente en el ámbito germánico, y estrechamente ligadas a problemáticas y tradiciones filosóficas idiosincrásicas que vale la pena reexaminar.

3.1. La filosotía moral. Así como la problemática contemporánea dentro de la que había surgido el interés filosófico por la teoría aristotélica de la acción estaba unida a las aporías a que había conducido la concepción "pictórica" de la proposición en su relación con el mundo, fundamentalmente cuando se trataba de dar cuenta de hechos tales como el 
deseo, la voluntad y la acción, de la misma manera la problemática filosófica dentro de la que surge el nuevo interés por la ética aristotélica como fuente de una corriente contemporánea, el así llamado «neoaristotelismo", ${ }^{21}$ está estrechamente conectada a las dificultades en que se vio envuelta la tradicional teoría de la subjetividad trascendental hacia comienzos de este siglo para dar cuenta del correlato entre los contenidos intencionales de la consciencia y la constitución de los objetos en el mundo. La forma más avanzada de esta teoría, la fenomenología de Husserl, había conducido a la más radical reducción del Yo trascendental del idealismo alemán a la mera unidad de la consciencia intencional ya en la V Investigación lógica, pero el resto solipsista, que desde el comienzo de la filosofía moderna había afectado permanentemente al paradigma de la consciencia, soportaba tenazmente los embates del maestro. ${ }^{22}$ Es precisamente en esa coyuntura en la que la categoría filosófica de la "vida", que habia dominado la escena desde fines del siglo xrx en adelante, se abre camino a través de los análisis fenomenológicos de Husserl y, especialmente, de su joven discípulo, $M$. Heidegger. No se trata, sin embargo, de la mera adopción del múltiple concepto, sino ya, desde el comienzo, de una elaboración que - sin duda a través de la mediación de la Fenomenología del Espiritu- se remonta al mismo Aristóteles. ${ }^{23}$ En efecto, "vida" es el modo de ser del sujeto en el mundo, y su existencia se da exclusivamente bajo la forma de la vida, que se encuentra a sí misma en el mundo entregada a la facticidad de una existencia que debe ser vivida. De ahí que la vida se desdoble en la vida activa que tiene que ser vivida y en el mundo del que se nutre esa vida, abriéndose en su "objetividad ». Para el joven Heidegger, la categoría de la vida tiene un punto central de referencia, que está constituido por la "preocupación» (Sorge), justamente por el mundo al que está arrojada. ${ }^{24}$ Los modos de esta referencia central son varios, y no vamos a perseguirlos en detalle. Lo decisivo es el violento giro que introduce en la propia consideración de la existencia humana. Ésta, en efecto, se convierte en un tipo de existencia caracterizada por la posibilidad de "comprender» el mundo y a sí misma en el mundo, "comprensión" que se extiende a las diversas posibilidades tanto de disposición pragmática de las cosas como de proyectos de la propia existencia, lo que en su conjunto abarca esa forma propia de autointerpretación que Heidegger denomina «hermenéutica de la facticidad". Gadamer ha puesto el acento sobre el decidido carácter de historicidad que toma ahora toda comprensión del sujeto humano. No se trata, ya, de un recurso metodológico propio de las ciencias del espiritu, como en Dilthey y el historicismo, sino de algo más radical: la pertenencia del intérprete al propio objeto de su interpretación no procede de una deficiencia estructural de las ciencias históricas, sino que es parte de la constitución de nuestra propia comprensión, de nuestra propia 
existencia. «También para la realización de la comprensión que tiene lugar en las ciencias del espíritu vale la idea de que la estructura del $D a$ sein es proyecto arrojado, y que el Dasein es, en la realización de su propio ser, comprender. La estructura general de la comprensión alcanza su concreción en la comprensión histórica en cuanto que en la comprensión misma son operantes las vinculaciones concretas de costumbre y tradición y las correspondientes posibilidades del propio futuro». ${ }^{25}$

Ahora bien, desde el comienzo mismo, este enérgico replanteo de la relación entre el hombre, su propia existencia y el mundo, llevaba un pesado lastre, que está anunciado en el análisis de la historicidad del Dasein en el $\$ 74$ de Ser y tiempo y se irá evidenciando paulatinamente en las manifestaciones públicas del filósofo hasta concluir con su discurso del rectorado y demás escritos de esta época (1933-1935). En efecto, el modo de ser abierto que tiene que ver con la acción, con la decisión y con la elección, es el cstado de decidido (Entschlossenheit) que abre la dimensión de la existencia auténtica. Esta decisión, empero, retrotrae al Dasein a su existencia fáctica, a su ser arrojado, cuya única posibilidad se abre a partír de su pasado, de la herencia histórica que él habrá de aceptar como su destino. ${ }^{26}$ De este modo, historicidad, decisión y finalidad última de la propia existencia quedaban drásticamente seccionadas de las conexiones en las que se hallaban en la tradición filosófica anterior, especialmente en la ética, y se convertían, en tanto modalidades fundamentales de la existencia humana, en categorías éticas absolutas, sobre las cuales no era posible encontrar otros fundamentos discursivos. ${ }^{27}$ Asi surge ese insidioso decisionalismo heideggeriano que paulatinamente se extiende de las decisiones individuales a las colectivas y termina abrazando la marcha cuya "majestuosidad y grandeza" él destaca en su discurso del rectorado. No nos interesa aquí examinar los motivos interiores al pensamiento de Heidegger que concluyeron en su conocida adhesión al nacionalsocialismo, sino el punto en el cual su análisis de la historicidad de la existencia humana deja el campo abierto para este radical rechazo de toda ética. Como han señalado con acierto Tugendhat y Habermas, este punto reside en su peculiar concepto de verdad como desocultamiento que no deja lugar para un concepto de validez, paralelo al de verdad, que comprenda las evaluaciones y las normas. En Heidegger no hay un concepto del «bien", de la «bondad" de los actos y de la "corrección" tanto de nuestras acciones con respecto a los otros como de las normas comunes. ${ }^{28}$ Esta falencia es compensada por medio de una terminología en la que predominan los vocablos duros y cuya punta está dirigida, fundamentalmente, a la vida institucional habitual de una sociedad democrática. Como señala W. Franzen, «toda esta actitud indica una fuerte tendencia a negarle a la vida práctico-burguesa los derechos que ésta requiere para sus necesidades, y que ella, en última ins- 
tancia, no solamente puede sino que debe reclamar. Desprecio es, en último término, lo que Heidegger opone al pragmatismo -en principio legítimo- de la normalidad ${ }^{29}$.

No resulta, pues, sorprendente que uno de los primeros trabajos en el que se anuncia la nueva tendencia que propugnará tender un puente entre la situación ético-política de la Alemania de postguerra y la filosofia práctica aristotélica lleve precisamente como título «La vida ciudadana (bürgerlich): sobre la teoría aristotélica de la felicidad». En él, Heidegger no es siquiera nombrado, a pesar de que la proveniencia conceptual y el clima en que se mueve están predeterminados por la problemática de Sein und Zeit, como algunos párrafos lo muestran casi textualmente: "praxis pertenece, de acuerdo con Aristóteles, a la esencia de todo lo viviente y no solamente del hombre, porque todo lo viviente realiza su naturaleza y aquello que por naturaleza puede ser, en la realización activa de su vidas. ${ }^{30}$ La punta polémica, sin embargo, aparece en una nota, en la que, al resaltar la validez de las opiniones comunes, Ritter afirma: «para ambos, para Aristóteles como para Hegel, vale la misma afirmación del ser en los entes, de modo que la inclinación de rechazar el «se» [das Man] como encubrimiento del ser «auténtico» por antonomasia aparece desde la visión de ambos como el abandono de la positividad de lo que es y de lo que acontece [...]n. ${ }^{31}$

3.2. La problemática que hemos expuesto sucintamente explica algunos de los rasgos definitorios de la corriente renovadora del aristotelismo ético o "neoaristotelismo», que es conveniente destacar. En primer lugar, un cierto radicalismo filosófico que evade todo posible contacto con posiciones o puntos de partida «universalistas» o «trascendentales», de cualquier carácter que éstas fuesen. Se trata, como dijimos, de una heredera de la hermenéutica radical heideggeriana, para la que sólo es admisible como estado inicial de toda búsqueda filosófica la historicidad fáctica y contingente de la existencia desnuda, el entrecruzamiento en ella de "lo dado" histórica y lingüísticamente. ${ }^{32}$ De allí, también, una primera cercanía al pensamiento ético-político de Aristóteles, en la medida en que éste piensa también las acciones históricas de los hombres con total ausencia de todo marco conceptual filosófico-histórico. «Tradición", "costumbres», "usos", la multiplicidad de lo vivido dentro del marco reunificador de la comunidad, de la polis, pasa a ser, entonces, el horizonte permanente y cambiante a un mismo tiempo desde el cual habrá de pensarse el modo especial de vida que es la prâxis humana.

En segundo lugar, esta prâxis nunca está aislada del marco institucional dentro del cual se realiza: será siempre una acción de un cierto miembro de la comunidad política en el interior de la polis y, por ende, estará ajustada a la costumbre o irá contra ella. La conexión entre êthos y éthos, a la que Aristóteles apela en el célebre comienzo del libro segun- 
do de la $E N$ (1.103a 17-18), es aquí explotada hasta sus últimas posibilidades (y, quizá, más allá de ellas) ${ }^{33}$ Estrechamente unido a éste, por fin, aparece la "virtud», justamente como ejercicio que forma al individuo en aquello que es común a todos y cuya posesión le convierte en miembro con pleno derecho de las instituciones de la vida pública: «la filosofía práctica de Aristóteles pregunta por lo bueno y lo legal como fundamento y medida de la virtud y de la vida buena y correcta así como de la àcción». ${ }^{34}$

En tercer lugar, el neoaristotelismo ha tomado de Hegel la polaridad entre subjetividad y objetividad, entre moralidad, por un lado, como principio de la infinitud del sujeto, y eticidad, por el otro, como fundamento concreto del espíritu objetivo. ${ }^{35}$ También aquí la filosofía práctica aristotélica ha servido de modelo, ya para Hegel mismo, al presentar una distinción entre individuo y Estado que es totalmente ajena a la contraposición moderna entre dos esferas infranqueables. ${ }^{36}$ Con este último tema está estrechamente unido, en cuarto lugar, el papel reservado por el neoaristotelismo a la phrónesis. En efecto, a partir de la afirmación de $E N$ VI 8, 1.141b 14-16 ("la sabiduría práctica no se ocupa solamente de lo general, sino que debe conocer también lo particular, pues es práctica y la praxis tiene que ver con lo particular»), la «inteligencia» práctica ha ocupado el lugar de un modelo de «razón hermenéutica» o «interpretativa", cuya función consiste en poder mediar entre lo general, incluido en el éthos, y las circunstancias particulares que caen, en cada caso, bajo la aplicación de la costumbre. Aristóteles mismo señala la estrecha conexión entre la facultad intelectiva y sus formas diversas de desempeño en la política, como legisladora, jurídica, etc. La diferencia consiste, nuevamente, en la radicalidad con la que se define esta facultad: ahora se la enfrenta a toda especie de razón práctica kantiana, es decir, a toda razón universalista que pretenda fundamentar normas universales basada, exclusivamente, en sus propios fundamentos discursivos. ${ }^{37}$

Así nos hemos ido acercando, en quinto y último lugar, al núcleo de la confrontación entre la rehabilitación neoaristotélica de la ética y la filosofía moral de la modernidad: la oposición entre "ser" y «deber ser". Como es sabido, tal fue, desde el comienzo de su reflexión en torno a la ética, el problema central para Hegel. Éste veía en la afirmación kantiana del deber ser (Sollen) sólo el reflejo de la reflexión en la consciencia subjetiva, tal que ésta, en el fondo, repelía toda objetividad, todo ser real. En efecto, para el sujeto, el fundamento de lo que él está obligado a realizar no es otro que la reflexión sobre la ley universal entendida como mera posibilidad pensada y ajena, por lo tanto, a la realidad, de modo que, en última instancia, el sujeto no reconoce otra autoridad sobre lo que constituye $s u$ deber que su propia convicción ni otro juez que su propia conciencia. ${ }^{38}$ De ahí que Hegel recurriera a Aristóteles y al antiguo éthos 
como la forma por antonomasia de la realización de la eticidad concreta e institucional por la que discurría la vida objetiva del espíritu. Ésta no era un mero "deber ser", que se esfumaba en el aire, sino una "substancia» que existía "exteriormente». Quizá sea éste el tema más recurrente en todas las corrientes que de un modo u otro reclaman el antecedente aristotélico para sus propias propuestas morales. En efecto, el ataque al "deber ser", al "imperativo categórico" y a toda otra forma de "universalismo» y "cognitivismo» moral termina, de un modo u otro, apoyándose en la moral aristotélica de la virtud como moral concreta que no requiere ni de especulaciones teóricas ni de fundamentaciones que vayan más allá de la particularidad de lo vivido. ${ }^{39}$

\section{Conclusión}

Si mi exposición anterior ha logrado transmitir de un modo coherente las sutiles uniones que van de la problemática filosófica contemporánea a la filosofía práctica aristotélica y a la inversa, es posible que el cuadro presentado sea, seguramente, único, si se lo compara con la presencia de cualquier otro pensador anterior a la época de la Ilustración en la filosofía contemporánea. Quizá dé este solo hecho la medida de la originalidad y profundidad de la obra del Estagirita en el ámbito de la filosofía práctica, fundamentalmente porque sus temas continúan siendo los temas en torno de los cuales sigue encendida la discusión; en la teoría de la acción, como hemos visto, por los fuertes impulsos que una posición como la aristotélica da para la explicación y comprensión de macroacciones, como las que protagonizamos en nuestra vida cotidiana de relación, frente a otras corrientes que pretenden, mediante sucesivas reducciones, abstracciones y otras diversas formas de seccionamiento artificial, aislar una especie de microelemento, la acción básica, directamente impenetrable a toda forma de entendimiento. En la filosofía moral, a su vez, la reactualización de la ética institucional de Aristóteles, menos feliz, a mi modo de ver en sus resultados, pone, sin embargo, el acento en una cuestión aún no resuelta de toda moral universalista: su corporización en las estructuras del «mundo de la vida». El «modelo» aristotélico tiene la ventaja sobre los otros modelos concurrentes, neohegelianos, comunitarios, etc., de haber trazado de modo transparente el entrecruzamiento entre sistemas de acción colectiva, normas consuetudinarias y formas de organización social y política (las famosas constituciones), sin partir de ninguna posición filosófico-histórica previamente tomada, pese a lo que afirmen algunos historiadores que no entienden de epistemología. ${ }^{40}$

Quisiera concluir mi revisión de la filosofía práctica aristotélica desde la perspectiva actual señalando un aspecto hasta el momento poco 
destacado, muy posiblemente por haber quedado a la sombra del conflicto entre las dos tendencias que traspasan su ética entera, es decir: la primacía de un fin exclusivo sobre un fin inclusivo en el desarrollo de la vida humana. Yo tomo partido, decididamente, por aquéllos que consideran imposible una moral a partir de la postulación de un fin exclusivo, la eudemonía. Pero, al mismo tiempo, creo que la presencia de ideales estéticos de realización personal y humana son imprescindibles para cualquier macroacción, personal o colectiva. En otros términos, los ideales de la vida buena forman parte indispensable de nuestras conductas tanto privadas como públicas (o de las ausencias de ellas), de modo tal que, si bien no es posible fundamentar una moral no relativista sobre la eudemonía, es imposible imaginarse una moral universalista que pueda realizarse sin el impulso de aquéllos.

\section{NOTAS}

1. Un excelente resumen del estado de la cuestión desde el punto de vista filológico ha sido dado recientemente por $H$. Flashar (1983), passim.

2. Cfr. Wittgenstein: Wkausg. I, p. 82.

3. Cfr. Wittgenstein: Wkausg. I, p. 183. Anscombe (1963), pp. 171 y ss.

4. Cfr. Winch (1972), pp. 123-124.

5. Cfr. Wittgenstein: Wkausg. I, p. 465.

6. Cfr. Winch (1972), pp. 127-129.

7. Cfr. Anscombe (1963), \& 35 y 29, pp. 52-53.

8. Cfr. Magna Moralia I 17, 1.189b 20-24 = EE II 10, 1.226a 33-b2.

9. Cfr. Wittgenstein, Philosophische Untersuchungen I 335 y 88, Wkausg. I, pp. 290-291; cfr. Pitcher (1964), pp. 176-177.

10. Cfr. Guariglia (1982), pp. 43-45.

11. Cfr. Gaiser (1963), pp. 104-106.

12. Para un análisis exhaustivo del capitulo, cfr. Kenny (1979), pp. 3-12.

13. Cfr. Anscombe (1963), pp. 9-21; Kenny (1979), pp. 27-66.

14. Cfr. Wiggins (1975-1976), pp. 215.237; Cooper (1975), pp. 1-88; Craven Nussbaum (1978), pp. 165-220; Kenny (1979), pp. 69-107; Engberg-Pedersen (1983), pp. 188-222.

15. Mi interpretación coincide en todo lo fundamental con la de Anscombe (1965), pp. 154-157 y Wiggins (1975-1976), pp. 224-227. No me parece, en cambio, tan sencillo decidir si la interpretación expuesta es la misma que sostiene Engberg-Pedersen (1983), pp. 192 y ss., en especial por la dificultad de entender qué significa para él unon-rational».

16. Cfr. Loening (1903), pp. 26-39; Allan (1953), pp. 120-127.

17. Cfr. Guariglia (1986a), pp. 104-105.

18. Cfr. Wiggins (1975-1976), p. 228.

19. Cfr. Cooper (1975), pp. 62, 76 y ss.

20. Cfr. Cooper (1975), pp. 77-88; Guariglia (1986b), pp. 104-108.

21. Cfr. Schnädelbach (1986), pp. 38 y ss.

22. Cfr. Husserl, Bd. XIX 1, pp. 355 y ss,; Bd. VI, pp. 168-170. La conexión interna entre la problemática fenomenológica, la filosofía de la vida de Dilthey, Yorck, el idealismo alemán y el joven Heidegger ha sido expuesta exhaustivamente por Gadamer (1960), pp. 229-250.

23. Cfr. De anima II 4, 415b 8-15; la conexión entre el concepto hegeliano de vida, la 
filosofía aristotélica y el punto de partida de la historicidad del Dasein en Heidegger aparece claramente reflejada en la tesis de habilitación del joven Marcuse bajo la dirección de aquél, Hegels Ontologie und die Theorie der Geschichtlichkeit, passim, pero especialmente la segunda parte. Toda mi exposición de la problemática heideggeriana en relación con la acción, la deliberación, etc., se guía fundamentalmente por la (brillante) interpretación de Tugendhat (1979), pp, 164-244.

24. Cfr. Heidegger, Bd. 61 , pp. 84 y ss.

25. Cfr. Gadamer (1960), p. 249.

26. Cfr. Heidegger, SuZ, pp. 382-384.

27. Cfr. Löwith, Bd. 8, pp. 142 y ss.; Tugendhat (1979), pp. 239-241.

28. Cfr. Tugendhat (1979), p. 239; Habermas (1985), pp. 158 y ss.

29. Cfr. Franzen (1988), p. 85.

30. Cfr. Ritter (1969), pp. 57 y ss.

31. Cfr. Ritter (1969), p. $65, n^{\circ} 12$.

32. Cfr. Gadamer (1960), pp. 295 y ss.; (1972), pp. 332 y ss.

33. Cfr. Ritter (1960), pp. 486 y ss.; (1969), pp. 110 y ss.

34. Ritter (1969), p. 112; cfr. Bien (1973), pp. 88 y ss., 218-243.

35. Cfr. Ritter (1969), pp. 291 y ss.

36. Cfr. Ritter (1960), pp. 487 y ss.; para una exégesis del texto central para la relación entre individuo y Estado en Aristóteles, $E N$ V 3, 1.129b 12-25, véase Allan (1965), pp. 68 y ss. y mi crítica en Guariglia (1976), pp. 155 y ss.

37. Cfr. Gadamer (1960), pp. 301-306; Bien (1973), pp. 132-138 y la critica de Schnädelbach (1986), pp. 54 y ss. a lo que él denomina "la ideología de la phrónesis".

38. Para un análisis exhaustivo de esta cuestión, remito a Guariglia (1986a), pp. 146 y ss. y 183 y ss.

39. Así ocurre también con la corriente neoaristotélica anglosajona, en especial con MacIntyre (1981), pp. 49 y ss.

40. Contra Day y Chambers (1967), cap. III.

\section{BIBLIOGRAFIA}

ARIstoteles: Ethica Nicomachea, I. Bywater (ed.), Oxford, 1894 (EN).

-: Ethica Eudemia, H. Rackham (ed.), Londres-Cambridge, Mass., 1935 (EE).

-: De anima, W.D. Ross (ed.), Oxford, 1956.

-: De motu animalium, M. Craven Nussbaum (ed. y comp.), Princeton, Princeton University Press, 1978.

Platon: Philebus, A. Dies (ed.), París, Belles Lettres, 1959 (Phil.).

Bibliografia secundaria

Allan D.J.: "Aristotle's Account of the Origin of Moral Principles", en Actes du XIeme Congrès International de Philosophie (Amsterdam-Lovaina), vol. XII (1953), 120-127.

-: "The Practical Syllogism», en Aufour d'A ristote, Lovaina, Public Univ. de Louvain, 1955, 325-340.

-: "Individual and State in the Ethics and the Politics", en La "Politique" d'Aristote, t. XI. Vandoeuvres-Ginebra, Entretiens Hardt, 1965, 53.86.

ANscombe G.E.M.: An Introduction to Wittgenstein's Tractatus, Nueva York, Harper \& Row, $1959^{2}$.

-: Intention, Oxford, Blackwell, $1963 .^{2}$

-: "Thought and Action in Aristotle", en R. Bambrough (ed): New Essays on Plato and Aristotle, Londres, Routledge \& Kegan Paul, 1965, 143-158. 
-: "Modern Moral Philosophy", en Collected Papers, vol. 3, Oxford, Blackwell 1981, 26-42. Aubenoue P.: La prudence chez Aristote, París, PUF, 1963.

BrEN G.: Die Grundlegung der politischen Philosophie bei Aristoteles, Friburgo-Munich, Alber, 1973.

CLARK S.R.L.: Aristotle's Man, Speculations upon Aristotelian Anthropology, Oxford, Clarendon Press, 1975.

COoper J.M.: Reason and Human Good in Aristotle, Cambridge, Mass.-Londres, Harvard U.P., 1975.

DaY J. y Chambers M.: A ristotle's History of Atheninan Democracy, Amsterdam, Hakkert, 1967.

Engrerg-Pedersen T: A ristotle's Theory of Moral Insight, Oxford, Clarendon Press, 1983.

Flashar H.: "Aristotcles», en Grundriss der Geschichte der Philosophie, vol. 3, BasileaStuttgart, Schwabe, 1983, 175.457.

Franzen W.: “Die Sehnsucht nach Härte und Schwere», en A. Gethmann-Siefert y O. Pöggeler (ed.): Heidegger und die praktische Philosophie, Francfort, Suhrkamp, 1988, 78-92.

Gadamer H.G.: Wahrheit und Methode, Tubinga, Mohr, 1960.

-: "Hermeneutik als praktische Philosophie», en M. Riedel (ed.): Rehabilitierang der prak. tischen Philosophie, Friburgo, Rombach, 1972, 325-345.

GaISER K.: Platons ungeschriebene Lehre, Stuttgart, Klett, 1963.

GUARIGLIA O: "La voluntad, el bien general y los fines individuales en la filosofia práctica de Aristóteles», Cuadernos de Filosofía (Buenos Aires), 13 (1973), 49-59.

-: «El concepto del bien en Aristóteles», Rev. Latinoam. Filos., 1 (1975), 152-163.

-: «Orden social jerárquico y norma consuetudinaria en el pensamiento ético-político de Aristóteles», Rev. Latinoam. Filos, 2 (1976), 121-168.

-: "Dominación y legitimación en la teoria política de Aristóteles ${ }_{,}$Rev. Latinoam. Filos., 5 (1979), 14.42.

-: "Paideia y dialéctica en la ética de Aristóteles», Dianoia, 28 (1982), 23-49.

-: "Notas sobre el concepto de justicia en Aristóteles", Anuario de Fitosofía Jurídica y Social, Buenos Aires, Abeledo-Perrot, 1982, 97-109.

-: "La teoría aristotélica de la acción: un enfoque actual ", Razón práctica (Carabobo, Valencia), 1 (1985), 1-11.

-: Ideologia, verdad y legitimación, Buenos Aires, Sudamericana, 1986a.

-: "¿Moral del deber o moral de la virtud?", Critica, 18 (1986b), 95-110.

-: "Razón práctica c intereses de la acción», Dianoia, 33 (1987), 53-68.

-: «El principio de universalización y la razón práctica» (1. " parte), Crítica, 20 (1988), $31-54$.

-: "El principio de universalización y la razón práctica" (2." parte), Crítica, 21 (1989), 3-41.

-: "Heidegger y el fascismon, Punto de Vista, 34 (jul-sept. 1989), 17-21.

Gómez-Loвo A.: "Deliberación y razonamiento moral en Aristóteles», Rev. Latinoam. Filos., $10(1984), 133-140$.

Habermas J.: Der philosophische Diskurs der Moderne, Francfort, Suhrkamp, 1975.

-: «Moralität und Sittlichkeit», en W. Kuhlmann (ed.): Moralität und Sittlichkeit, Francfort, Suhrkamp, 1986, 16-37.

HaRdie W.F.R.: Aristotle's Ethical Theory, Oxford, Clarendon P., 1965.

Heidegger M.: Sein und Zeit. Tubinga, Niemeyer, 1957 (SuZ).

--: Gesantausgabe, II, vol. 61: Phänomenologische Interpretationen zu Aristoteles (1921-1922), Francfort, Klostermann, 1985.

-: Gesamtausgabe, II, vol. 63: Ontologie (Hermenettik der Faktizität), Francfort, Klostermann, 1988.

HUSSERL E: Gesammelte Werke, vol. VI: Die Krisis der europäischen Wissenschaften und die traszendentale Phänomenologie, La Haya, M. Nijhoff, 1954.

-: Gesammelte Werke, vol. XIX-1: Logische Untersuchungen, La Haya, M. Nijhoff, 1984. 
ILting K.H.: "Hegels Auseinandersetzung mit der aristotelischen Politik", Philosophisches Jahrbuch, 71 (1963-1964), pp. 38-58.

KenNy A., Action, Emotion and Will, Londres, Routl. \& Kegan Paul, 1963.

-: Aristotle's Theory of the Will, Londres, Duckworth, 1979.

LOENING R.: Die Zurechnungslehre des Aristoteles, Jena, 1903 (reimpresión: Hildesheim, Olms, 1967).

LöwTн K.: Sämtliche Schriften, vol. 8: Heidegger-Denker in dürttiger Zeit, Stuttgart, Metzler, 1984.

MacInTYRe A.: After Virtue, Notxe Dame, Univ. Notre Dame P, 1981.

Moravcsik J.M.E. (ed.): Aristotle. A Collection of Critical Essays, Londres, Macmillan, 1968.

Nussbaum M.C.: "Practical Syllogisms and Practical Science", en Aristotle's. De motu animalium, Princeton, Princeton University Press, 1978. Interpretive Essay 4, 165-220.

-: The Fragility of Goodness, Cambridge, Cambridge UP, 1986.

Prtcher G.: The Philosophy of Wittgenstein, Englewood Cliffs, Prentice Hall, 1964.

RrTter J.: Metaphysik und Politik. Studien zu Aristoteles und Hegel, Francfort, Suhrkamp, 1969.

-: "Zur Grundlegung der praktischen Philosophic bei Aristoteles", Rehabilitierung der praktischen Philosophie, vol. II (1960), 479-500.

SCHNÄDELBACH H.: "Was ist Neoaristotelismus? ", en W. Kuhlmann (ed.): Moralität und Sittlichkeit, Francfort, Suhrkamp, 1986, 38-63.

Tugendehart E.: Selbstbewusstein und Selbstbestimmung, Francfort, Suhrkamp, 1979.

Wigcrns D.: «Deliberation and Practical Reason» (1975-1976), en Needs, Values, Truth, Oxford, Blackwell, 1987, 215-237.

Winch P.: "Wittgenstein's Treatment of the Will", en Ethics and Action, Londres, Routledge \& Kegan Paul, 1972, 110-130.

Wittgenstein L.: Werkausgabe, vol. 1. Francfort, Suhrkamp, 1989. 